\title{
Albanon
}

Revistë kulturore

\section{Kur 100 vjet më parë, u shfaq drama e parë shqipe në Elbasan}

\section{Drama "Besa" e Sami Frashërit - sukses dhe jehonë në gjithë vendin.}

Mblodhi dhe solli - Fetah Biza

Njëqind vjet më parë, më 25 korrik 1918, u shfaq drama e parë shqipe në qytetin e Elbasanit. Drama "Besa", me autor Sami Frashërin, u vu në skenë nga grupi themelues teatror i qytetit, i cili disa ditë më pas, më 4 gusht, mori emrin "Shoqënia Theatrore e Elbasanit". Duhet thënë, që kjo ngjarje e shënuar kulturore për Elbasanin, pati një sukses të madh dhe jehona e saj u përhap në të gjithë vendin. Kështu, drama u shfaq pak ditë më pas edhe në Shkodër, e pasqyruar kjo edhe në shtypin e kohës. Më poshtë, po japim një përmbledhje të kësaj drame, të autorëve realizues, interpretëve, subjektit e vlerave të saj, si edhe përcjelljes që ajo pati në opinion dhe shtypin e kohës.

(Materiali i mëposhtëm është marr nga origjinali, sipas gazetës "Posta $e$ Shqypnis" e Shkodrës, dhe Historia dhe poetika e dramës shqiptare,1886 1996, e Nebi Islamit).

Trupa dhe realizuesit e dramës "Besa", më 25 korrik, 1918, në Elbasan.

\begin{tabular}{|l|l|l|}
\hline Nr 1 & Titulli i dramës & Besa \\
\hline 1 & Dramaturg & Sami Frashëri \\
\hline 2 & Regjizor & Thanas Floqi \\
\hline 3 & Muzika & Thanas Floqi \\
\hline 4 & Skenograf dhe piktor & Thanas Floqi \\
\hline 5 & Përkthyes & Abdyl Ypi \\
\hline
\end{tabular}




\begin{tabular}{|c|c|c|c|}
\hline $\mathrm{Nr}$ & Personazhet & aktori që interpreton & profesioni \\
\hline 1 & Zyberi- i biri i Vahidesë & Sif Popa. & \\
\hline 2 & Vahideja- gruaja e Zyberit, 34 - 40 vjeç & Pjetër Ndria. & shkollar \\
\hline 3 & Manushe, e bija e Zyberit dhe Vahides 16-17 vjeç & Hasan Ceka. & shkollar \\
\hline 4 & Rexhepi, nipi i Zyberit 17-18 vjeç & Hysen Miraku. & shkollar \\
\hline 5 & Saideja, bija e një fqinje, 15-17 vjeç & Sif Dodbiba. & \\
\hline 6 & Demir Beu, nga paria e Tepelenës, 50-60 vjeç & Thanas Floqi, & drejtues i shkollës qandrore \\
\hline 7 & Selfo - i biri me shpirt. & Zef Mosi. & nënpunës i etappenpost \\
\hline 8 & Telhai, qahja i Demir Beut, 40 - 50 vjeç & & \\
\hline 9 & $\begin{array}{l}\text { Fetah agai, ushtar nga Borshi, babai i Selfos, } \\
45-50 \text { vjeç }\end{array}$ & Tef Leka. & shkrues i gjykatores \\
\hline 10 & Xhafoja - trima të Demir beut & Kolë Robja. & \\
\hline 11 & Sulçja - trima të Demir beut & & \\
\hline 12 & Asllani - trima të Demir beut & Sif Popa. & \\
\hline 13 & Rrapoja - trima të Demir beut & Peter Ndrija & shkollar \\
\hline 14 & Vrenozi - trima të Demir beut & Sif Popa. & \\
\hline 15 & Selmani, ushtar nga Borshi, 30 - 35 vjeç & Spiro Todri. & shkollar \\
\hline 16 & Duria - nëna e Fetah agait, 80 - 90 vjeç & Vasil Bici. & shkollar \\
\hline 17 & Nje xhandar kalorës & Andrea Athanas & \\
\hline
\end{tabular}

\section{Trupa dhe realizuesit e dramës "Besa”, në shfaqjen në Shkodër.}

\begin{tabular}{|l|l|l|l|}
\hline $\mathrm{Nr}$ & Personazhet & aktori që interpreton & profesioni \\
\hline 1 & Merushe e bija e Vahides & Hasan Ceka. & shkollar \\
\hline 2 & Zyberi, & Zef Mosi & nënpunës i etappenpost \\
\hline 3 & Demir Beu Fetah & Mustafa Curi & drejtues i shkollës qandrore \\
\hline 4 & Selfo & Tef Leka & shkrues i gjykatores së shkollës \\
\hline 5 & Duri & Niko Progri & drejtor i shkollës Beratit \\
\hline 6 & Vahide & Hysen Miraku & shkollar \\
\hline 7 & Selman e Talba & Spiro Todri & shkollar \\
\hline 8 & Rexhepi & Ali Cungu & shkronjës i katundarisë \\
\hline 9 & Saidê & Sif Dodbiba. & \\
\hline 10 & Asllani & Sif Popa. & \\
\hline
\end{tabular}




\section{ALBANON}

Revistë kulturore

\begin{tabular}{|l|l|l|l|}
\hline $\mathrm{Nr}$ & Personazhet & aktori që interpreton & profesioni \\
\hline 11 & (Rrapo) & Peter Ndrija & shkollar \\
\hline 12 & Xhako & Kol Robja. & \\
\hline 13 & Evrenos & Vasil Bici & \\
\hline 14 & Kalorës & Andrea Atanas & \\
\hline
\end{tabular}

\section{Ja ç’shkruan gazeta "Posta e Shkodrës", dt.3 gusht 1918}

Viti 1875 sjell një dramë në gjuhën turke me subjekt shqiptar, "Besa” të Sami Frashërit. Kjo vepër u botua në shqip në vitin 1901 dhe ushtroi një ndikim të madh në fushën e dramaturgjisë dhe teatrit dhe njihet si një nga dramat më të mira të periudhës të Rilindjes.

Argtim theatral në Elbasan. Më 26 korrik u-lujt këtu për herë të parë (Shkodër) drama shqipe "Besa" e Sami Bej Frashërit, e cila ka lânë përshtypje fort në dëgjonjësit. E treta e fitimevet i u dha kryqit të kuq të Monarkis. Rolet e dramës ishin da kështû (shih më lart).

Nga këto, talentet mâ të bukura i treguan, Z. Zef Mosi, Hasan Ceka, Tef Leka, Niko Progri, Hysejn Miraku, e Spiro Todri. Edhe të tjerët kanë lojtë fort bukur, por të parët kanë lujtë si me qenë aktorë të shprovuem. Amatorët e sipërmë janë lidhë në një shoqni theatrore edhe âsht shpresa se do t’a vazhdojnë për herë punën që kanë fillue, tyke dhanë shpesh herë represantatione, prej të cilavet ka për të fitue mjaft qytetnimi i vendit. Asht për tuj falë nderit Gruppen-Komandës ashtu Bezirks Komandes, e Etappen-Stations-Komandes të cilat na kanë nimue me landën e tuj na shlue dhe vëndin kû kemi shpres se muej kêmi me çfaqë ndoj sênd tue shtij në pûnë fitim për Kruç të Kuq e për të vorfunit e vendit dhe për çarkun Letrarë.

\section{A) Mendime të bashkëkohësve Abedin Çaushi}

Shfaqja e dramës "Besa" nga grupi ynë, pati shumë sukses. Ky sukses na nxiti të formojmë zyrtarisht shoqërinë teatrore, përpunova rregulloren e saj të cilën e quajtë "Kaninizëm” përmbatja e së cilës ishte në drejtimin kryesor të përmbatjes së lëvizjes theatrore në qytetin tonë. Kryetar u zgjodh Abedin Çaushi. 


\section{B) Vlerat ideoartistike të dramës}

Tragjedia me temë dhe subjekt nga jeta reale gjithashtu me gërshetime dhe reflekse të elementeve mitike që ngrihen deri në rrafshe teokozmagonike me shtrirje kohore të periudhës pagane, por me influencë të fuqishme në vetëdijen shoqërore dhe në raportet e kohës janë shprehur me shkathtësi në dramën "Besa" (1902) e cila një kohë është konsideruar dram e parë shqiptare.

Ajo sjellë një temë dhe subjekt nga tradita shqiptare të lidhur me Besën e cila është ngulitur thellë në vetëdijen kolektive dhe ka marrë formë të institucionalizuar. Në këtë kontekst zhvillohet fabula e tragjedisë e cila lidhet me dashurinë, urrejtjen krimin, hakmarrjen dhe tragjedinë. Drama, si njera ndër përpjekjet e para të kësaj gjinie, ka arritur të rrahë çështje fundamentale me të cilat ka sjellë botkuptime filozofike, etike dhe psikologjike por edhe ide metafizike me të cilat pasqyrohen mënyra e ekzistencës dhe e kulturës kolektive e individuale të shqiptarëve të kodifikuara edhe me norma kanunore autoktone

\section{C) Rreth përmbajtjes së dramës}

Rexhepi i cili dashuron Manushen të bijën e Vahides, pengohet nga Demir Beu i cili lakmon që atë ta martojë me Selfon që e ka bir shpirti.

Fetahu, i jati i Selfos është mik i Vahidesë dhe pas 20 vjetësh kthehet në fshat. Ai për një të mirë të dikurshme, kur Vahideja ia kishte shpëtuar jetën, ia kishte dhënë fjalën (besën) se do t’i dilte në ndihmë sa herë që të jetë nevoja.

Pikërisht në këto çaste Demir beu dhe Selfo i bijnë në qafë asaj dhe të birit Zyberit, ndërsa Selfo që është egoist i tërbuar dhe lakmiqar ka vendosur që me çdo kusht ta marrë Manushaqen qoftë edhe duke e rrëmbyer.

Zyberi që i urren tipat e Demir Beut dhe të Selfos jo vetëm për motivet e tyre konkrete, por edhe për arsye se janë parazitë dhe se jetojnë nga dhuna dhe qelepirët që i nxjerrin nga njerëzit e ndershëm e shfryn mllefin mbi Demir beun i cili më tutje e nxitë Selfon që t’i hakëmerret kurse ky për motive më të ulëta e vret. 


\section{Albanon}

Revistë kulturore

Më tutje ngjarja zhvillohet në mënyrë që Fetahu, besnik ndaj fjalës së dhënë - besës, e vret të birin për t’ia marrë gjakun Zyberit, por e vret edhe veten për ta larë "gjakun me gjak".

Sipas: Historia dhe poetika e dramës shqiptare $(1886$ - 1996) nga Nebi Islami botimi: Art; Prishtinë 2003.

Faqe 68 - 69. N.I. 